\title{
THE INFLUENCE OF PARTICLE SIZE AND FRICTIONAL/ COHESIONAL SHEAR STRENGTH COMPONENTS ON UK SALT MARSH SUBSTRATE STABILITY
}

\author{
HELEN BROOKS ${ }^{1}$, IRIS MÖLLER ${ }^{1}$, TOM SPENCER $^{1}$, KATHERINE ROYSE $^{2}$, \\ MATTHEW KIRKHAM ${ }^{2}$, SIMON JAMES PRICE ${ }^{3}$
}

1. Department of Geography, University of Cambridge, Downing Place, Cambridge, CB23EN,UK.hyb20@cam.ac.uk.

2. British Geological Survey. Nicker Hill, Keyworth, Nottingham, NG12 5GG, UK. k.royse@bgs.ac.uk

3. Arup. Fitzroy Street, London, W1T 4BQ, UK. Simon.Price@arup.com

\begin{abstract}
Salt marshes and tidal flats contribute valuable ecosystem services, by providing habitats, storing pollutants and reducing flood and erosion risk in the coastal hinterland. However, salt marsh areal extent is decreasing both globally and regionally (e.g. in Northwest Europe). While we know that salt marshes are retreating, this could be occurring due to biological, geochemical and geotechnical properties of the marsh and tidal flat, and/or due to changes in hydrodynamic forcing. Until now, very few studies have assessed how substrate geotechnical properties influence both the erosion processes and the erodibility of the marsh edge and tidal flat surface. Here, we compare frictional and cohesional strength components at two hydrodynamically-similar but sedimentologically-different salt marshes and tidal flats in the UK. As such, we assess how sediment composition and behavior may influence marsh resistance to hydrodynamic forcing.
\end{abstract}

\section{Introduction}

Salt marshes sequester carbon (McLeod et al. 2011), store pollutants (Crooks et al. 2011) and provide habitats (Barbier et al. 2011). Marshes and tidal flats also attenuate incoming hydrodynamic energy (Möller et al. 2014). As a result, where marshes and tidal flats exist seaward of a seawall, these landforms often constitute an important component of the flood protection plan, as the protection afforded by the sea wall also depends on the marsh width and elevation. This is known as a 'hybrid' engineering solution, or as nature-based coastal protection.

However, marshes are declining both globally and regionally (Blankespoor et al. 2014; Crosby et al. 2016; Spencer et al. 2016), so an ability to model future change in marsh extent is becoming increasingly important. While many studies have considered the hydrodynamic forces acting on marshes (Möller \& Spencer 2002; Leonardi \& Fagherazzi 2014; Hunt et al. 2015), and the contribution of biology to marsh stability (Chen et al. 2017; Willemsen et al. 2018), few have assessed the role of substrate properties. Those studies which do assess marsh and tidal flat substrate erodibility (e.g. Crooks \& Pye 2000; Howes et al. 2010) frequently rely on measures which quantify erosion thresholds for suspension of 
particles in the field (Tolhurst et al. 1999) or in annular flumes in the lab (Widdows et al. 2000; Thompson et al. in press). While these provide important insights into substrate erodibility, and particularly the role of biofilms, research has highlighted that little sediment erosion occurs at the marsh surface (Kirwan et al. 2010; Spencer et al. 2015) but rather at the marsh edge, through processes such as cliff undercutting and gravitational slumping (Allen 2000; Mariotti \& Fagherazzi 2013; Leonardi et al. 2018). As such, it is likely that models simulating salt marsh change under different future climate forcing scenarios could be improved, by using erodibility coefficients which are based on measured geotechnical and sedimentological properties.

The application of geotechnical methods (Terzaghi et al. 1996) to assess the physical composition and behavior of a substrate is used here to determine key geotechnical properties and behavior that may influence the stability of salt marshes and their resilience to erosion. These methods include the measurement and analysis of shear strength, in terms of their Mohr-Coulomb components of friction and cohesion. Therefore, the geotechnical analysis of salt marsh substrate properties and behavior is an important component that needs to inform future estimations of marsh extent resulting from environmental change.

This research is thus of relevance to the quantification of nature-based coastal protection schemes in light of future alterations in climate forcing, such as shifts in storminess or an increased base water level due to sea-level rise. To undertake the geotechnical analysis, two UK sites were chosen.

\section{Field sites}

\section{Tillingham Marsh, Essex}

Tillingham Marsh is an open coast marsh on the Dengie Peninsula, Essex, UK (Fig.1) with a Mean Spring Tide Range of 4.8m (Reed 1988). Möller \& Spencer (2002) recorded water depths of 0.12-0.84 $\mathrm{m}$ and mean (maximum) significant wave heights of 26 (86) cm from September 2000 to July 2001 at the vegetated marsh edge. Relative sea-level rise is estimated at 2-3 $\mathrm{mm} \mathrm{yr}^{-1}$ (Burningham \& French 2011) which, compounded by coastal ecosystems and local geomorphic setting (see Spencer et al. 2014), may intensify storm surge impacts. Tillingham Marsh vegetation includes, but is not limited to Aster tripolium, Salicornia spp., Puccinellia maritima, Elymus athericus, Atriplex portulacoides and Spartina anglica (Möller, 2006; Rupprecht et al. 2015). The marsh is ungrazed, siltdominated and has an above ground biomass of $0.27 \pm 0.15 \mathrm{~kg}$ dry weight $\mathrm{m}^{-2}$ (Ford et al. 2016).

The marsh-mudflat transition is characterized by well-developed shore-normal 
ridge-runnel morphology (Möller 2006). Over the past 100-150 years, the marsh has demonstrated dynamic behavior, with evidence of advancing and retreating phases (Harmsworth \& Long 1986; Pye 2000). However, the past ca. 40 years have been dominated by lateral retreat, which has occurred despite vertical accretion (Callaway et al. 1996; Evans 2018).

\section{Warton Marsh, North Lancashire}

Warton Marsh is an open coast marsh in the East of Morecambe Bay, north-west England (Fig. 1). The marsh edge cliff at Warton is approximately $2 \mathrm{~m}$ high and the marsh is dominated by Puccinellia maritima, particularly at the marsh edge. The marsh is sand-dominated, has an above-ground biomass of $0.09 \pm 0.21 \mathrm{~kg}$ dry weight $\mathrm{m}^{-2}$ and is grazed by sheep, with about 4-5 sheep per hectare (Ford et al. 2016). In Morecambe Bay the Mean Spring Tide Range is $8.4 \mathrm{~m}$ (Allen 1989 ) and, due to isostatic rebound, relative sea-level is still falling at a rate of $0.69 \mathrm{~mm} \mathrm{yr}^{-1}$ (Shennan \& Horton 2002). Since 1845, Morecambe Bay marshes have undergone alternating phases of erosion and expansion within an overall trend of increasing marsh extent (Gray 1972). The dynamic behavior of these marshes may relate to channel shifts within the Bay (Pringle 1995).

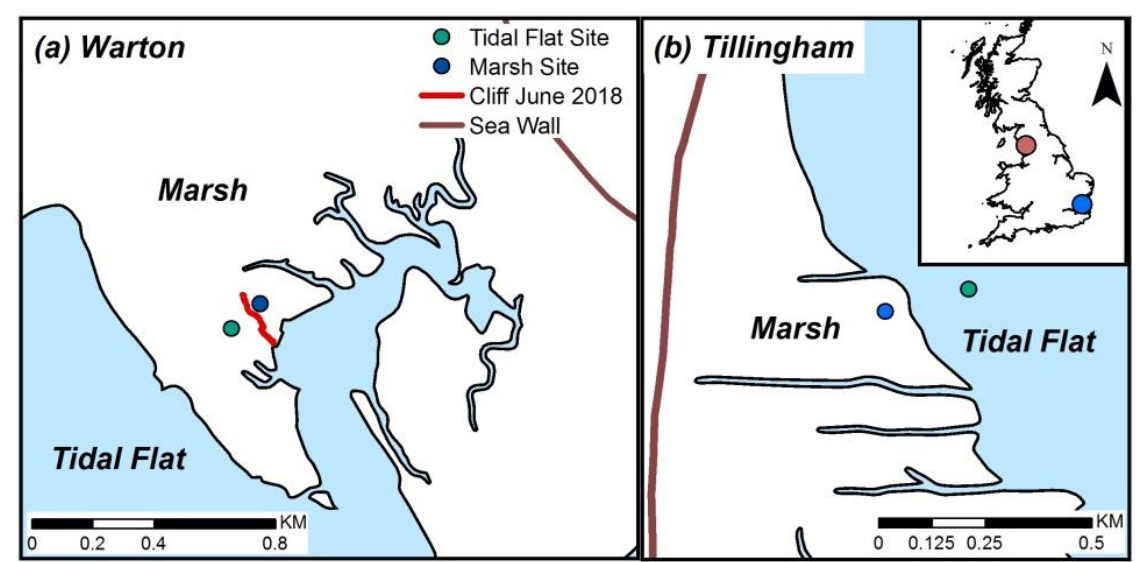

Fig. 1: Marsh and tidal flat sites at Tillingham Marsh (blue dot on inset) and Warton marsh (red dot on inset). Basemap uses OS (2018). Red line shows Warton cliff position surveyed in June 2018.

\section{Methods}

Class 1 undisturbed geotechnical samples (200 mm x $200 \mathrm{~mm}$ x $100 \mathrm{~mm}$ ) were extracted from Tillingham Marsh in September 2017 and from Warton Marsh in July 2018. Undisturbed samples were taken between 0-30 cm and 30-60 cm depth below ground level on each marsh, and at $0-30 \mathrm{~cm}$ depth on the tidal flat, in accordance with BS 5930:2015 (BSI 2015). Marsh sites were located within 
$50 \mathrm{~m}$ of the marsh edge (Fig. 1). To minimize disturbance during transport to the laboratory, samples were placed on trays and packed in Bubble Wrap ${ }^{\mathrm{TM}}$. Upon return from the field, samples were refrigerated at $5^{\circ} \mathrm{C}$, then sample color and composition was described following BS 5930:2015 (BSI 2015).

Particle size data from Wood et al. (2015) was used for this study. Three replicate surface samples were taken from twenty two locations at each sampling site (Tillingham tidal flat, Tillingham marsh, Warton tidal flat, Warton marsh) in both winter and summer of 2013. Each sample was pre-treated with $>30 \% \mathrm{w} / \mathrm{v}$ hydrogen peroxide overnight and then heated at $90^{\circ} \mathrm{C}$ in a water bath for two hours to remove organic matter. Samples were centrifuged and water was decanted, then $4.4 \%$ sodium hexametaphosphate was used as a deflocculating agent. Samples were analyzed using a Malvern Mastersizer 2000. The uniformity coefficient $\left(\mathrm{U}_{\mathrm{c}}\right)$ was calculated from particle-size data, where:

$$
U_{c}=D_{60} / D_{10}
$$

Undisturbed field samples for shear box tests were subsampled by trimming in the laboratory to fit a $100 \mathrm{~mm} \times 100 \mathrm{~mm} \times 20 \mathrm{~mm}$ shear box, and the test method followed BS 1377-7 (BSI, 1990). The shear rate for each test stage was dictated by $\mathrm{T}_{100}$ (time taken for $100 \%$ consolidation, assuming that primary consolidation continued throughout; Bishop \& Henkel 1962). This ensured that the displacement rate remained slow enough to permit the dissipation of excess pore-water pressure, thus allowing the assumption of zero pore water pressure and constant normal effective stress, $\sigma_{\mathrm{n}}$ ', throughout each test. Relatively low normal stresses $\left(\sigma_{\mathrm{n}}\right)$ were applied to each specimen, with $10 \mathrm{kPa}$ being applied to the first specimen, then $20 \mathrm{kPa}$ and $40 \mathrm{kPa}$ to the second and third specimens respectively. This typified effective stresses equivalent to $1 \mathrm{~m}, 2 \mathrm{~m}$ and $4 \mathrm{~m}$ water overburden, or approximately $0.5 \mathrm{~m}, 1 \mathrm{~m}$ and $2 \mathrm{~m}$ sediment overburden, respectively. For each specimen, peak shear strengths were plotted to construct a failure envelope determined by the Mohr-Coulomb equation:

$$
\tau_{f}=c^{\prime}+\sigma_{n}{ }^{\prime} \tan \varphi^{\prime}
$$

where: $\tau_{f}=$ shear strength, $c^{\prime}=$ effective cohesion, $\sigma_{n}{ }^{\prime}=$ normal effective stress, $\varphi^{\prime}=$ angle of shearing resistance (internal friction angle).

Ring shear samples were prepared from the trimmings of the second shear box specimen. Trimmings were sieved at $1.18 \mathrm{~mm}$ to remove roots and any larger particles, in accordance with BS 1377-7 (BSI 1990). As with the shear box test, the shear rate for each test stage was dictated by $\mathrm{T}_{100}$, to allow drainage. The test procedure followed that detailed in BS 1377-7 (BSI 1990) and was undertaken using the smallest possible normal stresses, resulting in a normal stresses of 14.4 $\mathrm{kPa}, 26.6 \mathrm{kPa}$ and $51.1 \mathrm{kPa}$ for specimen one, two and three, respectively. As 
the residual cohesion is assumed to be zero (Lupini et al. 1981; Tiwari \& Marui 2005), the residual strength was determined from:

$$
\tau_{r}=\sigma_{n}{ }^{\prime} \tan \varphi_{r}{ }^{\prime}
$$

where: $\tau_{r}=$ residual shear strength, $\sigma_{n}{ }^{\prime}=$ normal effective stress, $\varphi_{r}{ }^{\prime}=$ residual angle of shearing resistance (residual friction angle).

\section{Results}

Based on BS 5930:2015 (BSI 2015), the substrate at Tillingham was a very soft dark brown clayey silt with rootlets and lenses of clay. At Warton, the substrate comprised medium dense light greyish brown silty fine sand with rootlets and lenses of both clay and coarser sand. Particle size data denote that Tillingham marsh is composed of a Very Fine Sandy Medium Silt (d50=14.75 $\mu \mathrm{m})$, while Tillingham tidal flat is comprises a Very Fine Sandy Very Coarse Silt (d50=46.7 $\mu \mathrm{m})$. Both the marsh and tidal flat at Warton consist of Very Coarse Silty Very Fine Sand (d50 of $66.1 \mu \mathrm{m}$ and $89.7 \mu \mathrm{m}$, respectively). The particle size distribution (Fig. 2) at Tillingham marsh and tidal flat is platykurtic to mesokurtic (kurtosis=0.9-1.0 $\mu \mathrm{m}$ ), while the distribution at Warton marsh is very leptokurtic (kurtosis $=1.7 \mu \mathrm{m}$ ). Warton tidal flat has a kurtosis of $1.1 \mu \mathrm{m}$. The $U_{c}$ at Tillingham was higher than $U_{c}$ at Warton (Table 1). At both field sites, the d50 grain size on the tidal flat was coarser than that on the marsh, and grain size was coarser at Warton than at Tillingham (Table 1).

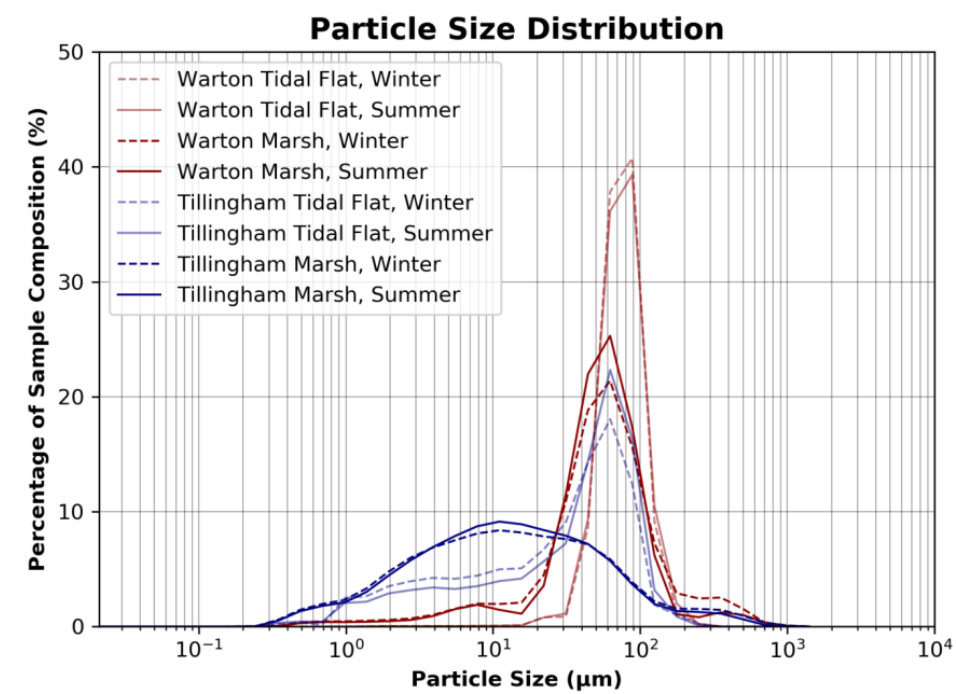

Fig. 2: Particle size analysis for Tillingham and Warton tidal flat and salt marsh in both Winter and Summer. Data from: Wood et al. (2015). 
Table 1: Median particle size $(\mathrm{d} 50$; in $\mu \mathrm{m})$ and uniformity coefficient $\left(\mathrm{U}_{\mathrm{c}}\right)$ at Tillingham and Warton tidal flat and salt marsh during Winter and Summer.

\begin{tabular}{lllll}
\hline & $\begin{array}{l}\text { Tidal Flat, } \\
\text { Winter }\end{array}$ & $\begin{array}{l}\text { Tidal Flat, } \\
\text { Summer }\end{array}$ & $\begin{array}{l}\text { Salt Marsh, } \\
\text { Winter }\end{array}$ & $\begin{array}{l}\text { Salt Marsh, } \\
\text { Summer }\end{array}$ \\
\hline Tillingham (d50) & 40.8 & 52.6 & 14.8 & 14.7 \\
Warton (d50) & 89.4 & 90.0 & 66.7 & 65.5 \\
Tillingham $\left(\mathrm{U}_{\mathrm{c}}\right)$ & 19.0 & 19.6 & 11.5 & 10.7 \\
Warton $\left(\mathrm{U}_{\mathrm{c}}\right)$ & 1.6 & 1.6 & 4.3 & 3 \\
\hline
\end{tabular}

Stress-strain curves from the shear box tests indicate that the substrate at both marsh sites exhibits elasto-plastic behavior. Mohr-Coulomb failure envelopes from the shear box tests suggest a low cohesional shear strength component ( $\left.c^{\prime}\right)$ at both sites, with all $c^{\prime}$ values being below $7.0 \mathrm{kPa}$ (Table 2). At both sites, $c^{\prime}$ was lower on the tidal flat than the marsh. The peak angle of shearing resistance $\left(\varphi^{\prime}\right)$ ranged between $29.9^{\circ}$ and $36.1^{\circ}$ at Tillingham, but was slightly higher at Warton, ranging between $33.4^{\circ}$ and $43.5^{\circ}$ (Table 2).

Table 2. Friction angle, cohesional strength and residual friction angle at Tillingham and Warton, as determined by shear box and ring shear tests.

\begin{tabular}{lllllll}
\hline \multicolumn{3}{c}{ Tillingham } & \multicolumn{3}{c}{ Warton } \\
\hline & $\begin{array}{l}\text { Marsh, } \\
\mathbf{0 - 3 0} \mathbf{~ c m}\end{array}$ & $\begin{array}{l}\text { Marsh, 30- } \\
\mathbf{6 0} \mathbf{~ c m}\end{array}$ & $\begin{array}{l}\text { Flat, 0- } \\
\mathbf{3 0} \mathbf{~ c m}\end{array}$ & $\begin{array}{l}\text { Marsh, } \\
\mathbf{0 - 3 0} \mathbf{~ c m}\end{array}$ & $\begin{array}{l}\text { Marsh, 30- } \\
\mathbf{6 0} \mathbf{~ c m}\end{array}$ & $\begin{array}{l}\text { Flat, 0- } \\
\mathbf{3 0} \mathbf{~ c m}\end{array}$ \\
\hline$\varphi^{\prime}\left({ }^{\circ}\right)$ & 35.3 & 29.9 & 36.1 & 43.5 & 36.1 & 33.4 \\
$c^{\prime}(\mathrm{kPa})$ & 2.1 & 5.7 & 0 & 6.6 & 6.8 & 2.9 \\
$\varphi_{r}^{\prime}\left({ }^{\circ}\right)$ & 29.4 & 28.2 & 33.3 & 31.4 & 33.8 & 28.8 \\
$\varphi^{\prime}-\varphi_{r}{ }^{\prime}\left({ }^{\circ}\right)$ & 5.9 & 1.7 & 2.8 & 12.1 & 2.3 & 4.6 \\
\hline
\end{tabular}

* All values are given to one decimal place.

The failure envelopes for the ring shear tests indicated that the residual angle of shearing resistance $\left(\varphi_{r}{ }^{\prime}\right)$ was lower than $\varphi^{\prime}$ at all sites (Table 2). The largest difference between $\varphi_{r}^{\prime}$ and $\varphi^{\prime}$ was at $0-30 \mathrm{~cm}$ depth on the marsh surface. 


\section{Discussion}

In all locations, the substrate exhibited elasto-plastic behavior. Therefore, the material required constant application of stress throughout the test to produce deformation. This suggests that, when undercut through tidal flat lowering and wave/tide action at the margin (in open coast settings) or through creek bank incision, the substrate would fail in a ductile manner, rather than by rapid, brittle failure. Although such marsh edge failure may produce block failures, these would likely continue to be partially connected to the marsh after initial failure, for example due to tensional strength provided by the roots. This agrees with Allen (1989) who noted the importance of the dense root mat near the surface which prevents tension cracks in the lower sequence from reaching the surface in Morecambe Bay. Examples of such features can be seen at the marsh edge at Warton (Fig. 3a). After continual scouring and erosion of the point of contact to the main marsh platform, these failed blocks may eventually become disconnected from the marsh platform, allowing new marsh edge substrates to be subjected to hydrodynamic forcing. The transition between the marsh and the tidal flat at Tillingham is characterized by mud-mounds, with little to no undercutting or marsh overhangs visible. It is possible that both the elastoplastic behavior of the surface substrate as well as slow rates of tidal flat lowering relative to the elevation of the marsh platform have contributed to the formation of this morphology.

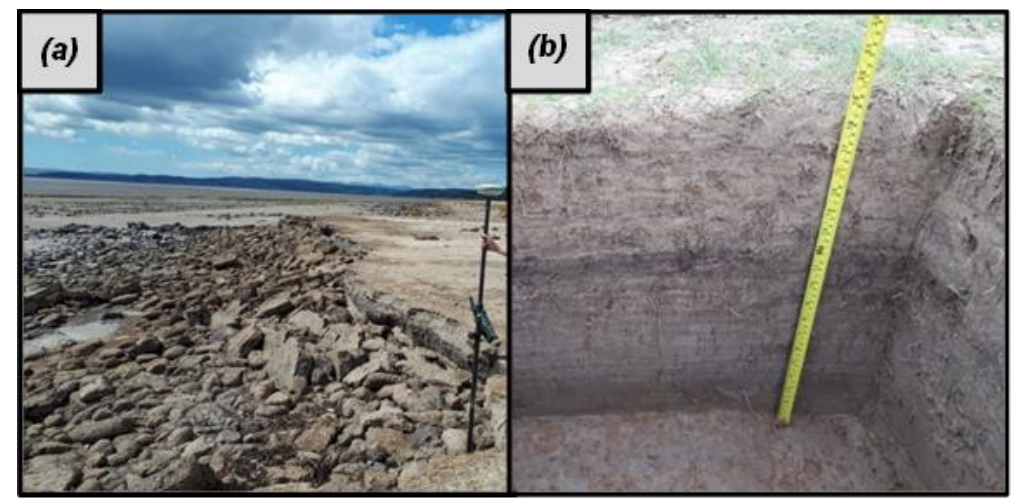

Fig. 3: (a) Failures along marsh edge at Warton marsh, North Lancashire. (b) Stratigraphy at the marsh sampling site at Warton. Photos: H Brooks.

At both sites, $c^{\prime}$ is low. For 0-30 $\mathrm{cm}$ at Tillingham Marsh and tidal flat, $c^{\prime}$ and $\varphi^{\prime}$ most closely represent a uniform, coarse, medium fine or silty sand (Hoek \& Bray 1974). The lower $\varphi$ ' at 30-60 $\mathrm{cm}$ depth at Tillingham Marsh may reflect a finer, dry sand. These classifications agree with surface particle size data, which showed the tidal flat to be composed of silt and sand, while the marsh was predominantly silt with some sand and very little clay (Fig. 2). 
At Warton, the tidal flat substrate and the substrate at depth on the marsh again likely represent uniform, coarse, medium fine or silty sands (Hoek \& Bray 1974). In contrast, the higher $\varphi^{\prime}\left(43.5^{\circ}\right)$ at $0-30 \mathrm{~cm}$ depth at Warton may denote a more compacted, well-graded, uniform sand (Hoek \& Bray 1974). While the surface particle size data agrees that the substrate is a fine sand on the tidal flat, it conversely shows that the marsh surface substrate is finer (Fig. 2). As a finer median particle size would usually be associated with a lower $\varphi^{\prime}$ (Barnes 2010) and this is not the case (Table 1), this implies that the increased $\varphi$ ' on the marsh surface may not be due to differences in the grain size, but rather due to either greater compaction or due to root properties. It is possible that the greater $\varphi$ ' on the marsh surface compared to the $\varphi$ ' at depth reflects compaction of the upper marsh stratigraphy due to grazing. Compaction by grazing is a well-known effect (e.g. Lambert 2000) and occurs due to the repeated trampling by animals. When compacted, there is greater interlocking between grains and therefore greater friction between the grains at particle contacts. As such, $\varphi$ ' is expected to be higher (Knappett \& Craig 2012). While some compaction is expected in deeper sediment layers due to autocompaction (compaction of the sediment under its own weight; Allen 1999), grazing-induced compaction at depth has been found to be negligible or absent (e.g. below $20 \mathrm{~cm}$ depth; Elschot et al. 2013). Photographs of the Warton marsh stratigraphy highlight a notable change in color at around $20 \mathrm{~cm}$ depth (Fig. 3b), and therefore potentially changes in other substrate properties, such as compaction or particle size. To further assess the effects of grazing on compaction and thus, potentially, frictional strength at this site, a comparison of the consolidation and particle size characteristics of present-day, grazing-affected surface sediments with sediments derived from layers that pre-date grazing at Warton would be beneficial.

The $\varphi$ ' was consistently higher at Warton than at the equivalent locations at Tillingham. This can possibly be explained by sedimentological or biological factors, or a combination of both. Given that $\varphi_{r}$ ' is also higher at Warton, this may imply that the explanation is sedimentological, rather than due to the impact of roots. Both larger particle sizes and a higher $U_{c}$ can increase the $\varphi$ ' of a substrate (Barnes 2010; Kara et al. 2013). While the larger d50 at Warton could contribute to a higher $\varphi^{\prime}$, the $U_{c}$ is lower at Warton. The lower $U_{c}$ at Warton signifies that the substrate has less particle size variation and therefore particles will likely be less interlocked and have fewer interparticle contacts for a given normal load, compared to the substrate at Tillingham. Therefore, based on $\mathrm{U}_{\mathrm{c}}$ alone, a lower $\varphi^{\prime}$ would be expected at Warton, contrary to what is observed. The above explanation of compaction due to grazing could also explain the higher $\varphi$ ' of the marsh sediments at Warton, compared to the ungrazed marsh at Tillingham.

The $c$ ' was lower on the tidal flat at both sites, in comparison to the salt marsh. 
As $c^{\prime}$ reflects the electrostatic forces between particles, particularly between clays, this could simply reflect the reduced clay content in the substrate on the tidal flat, compared to the marsh at both sites (Fig. 2).

In all cases, $\varphi_{r}{ }^{\prime}$ is lower than $\varphi^{\prime}$. Normally this reflects the clay bordering the failure plane as it softens and attains the critical state, along with reorientation of clay platelets parallel to the failure plane (Knappett \& Craig 2012). However, here, the shear box test reflects an undisturbed sample with intact roots, whereas the ring shear sample comprised only the sediment component of the substrate. As such, it is possible that the removal of roots contributes to this loss of frictional strength. This is corroborated by the fact that the largest decrease in $\varphi$ ' from the peak to the residual scenario occurred at the marsh surface, where the root mass was greatest (Table 2). While we know that roots increase the stabilize the marsh surface landward of the marsh edge (Ford et al. 2016), it has been proposed that roots can aid erosion at the marsh edge, when exposed and subjected to waves (Feagin et al. 2009). As such, it is important that models incorporate and quantify this dual role played by roots.

The results presented here are comparable to estuarine silts at Bothkennar, where $c^{\prime}=1.5 \mathrm{kPa}, \varphi^{\prime}=34^{\circ}$ and $\varphi_{r}{ }^{\prime}=30^{\circ}$ (Lehane \& Jardine 1992; Hight et al. 2003). The high angle of shearing resistance for both peak and residual values at Bothkennar, Warton and Tillingham may link to a high angular grain content and low platey clay content, however could also be reflecting root mass properties. Particle size and root content appear to influence substrate shear strength and may therefore have implications for salt marsh stability.

\section{Conclusion}

The above data demonstrate the value of accurate geotechnical information for the interpretation of modes of salt marsh erosion. Without information on the sedimentary properties and the geotechnical behavior of marsh and tidal flat substrates when these come under mechanical stress, it will not be possible to fully understand likely marsh and tidal flat stability, particularly under future wave impact scenarios. We present an initial analysis of substrate properties in two hydrodynamically-similar but sedimentologically-different marsh locations. Results will feed into a larger comparative study comprising detailed particle size analysis, loss on ignition, undrained shear strength tests, cohesive strength meter tests, consistency limits and consolidation tests. In doing so, we hope to be able to link spatial variations in substrate characteristics to observed vertical and lateral erosion on exposed salt marsh margins. Future models of salt marsh retreat under particular environmental change scenarios should benefit from such an improved understanding of marsh behavior under mechanical forcing. 


\section{Acknowledgements}

This work was funded by a NERC PhD studentship (LCAG/329; 2016-2020), and a Collaborative Award in Science and Engineering with the British Geological Survey (LCAG/352). The authors wish to thank Elizabeth Christie, Ben Evans, Sam Bithell, James Pollard and Amy McGuire for help with field work, and Steve Boreham and Lee Jones for help with laboratory work. Grain size data was provided by the NERC CBESS project (NE/J015423/1).

\section{References}

Allen, J. R. L. (1989). Evolution of salt-marsh cliffs in muddy and sandy systems: A qualitative comparison of British West-Coast estuaries. Earth Surface Processes and Landforms, 14(1), 85-92.

Allen, J. R. L. (1999). Geological impacts on coastal wetland landscapes: Some general effects of sediment autocompaction in the Holocene of northwest Europe. The Holocene, 9(1), 1-12.

Allen, J. R. L. (2000). Morphodynamics of Holocene salt marshes: A review sketch from the Atlantic and Southern North Sea coasts of Europe. Quaternary Science Reviews, 19(12), 1155-1231.

Barbier, E. B., Hacker, S. D., Kennedy, C., Kock, E. W., Stier, A. C. \& Silliman, B. R. (2011). The value of estuarine and coastal ecosystem services. Ecological Monographs, 81(2), 169-193.

Barnes, G. (2010). Soil Mechanics: principles and Practice (3rd Editio). Basingstoke, Palgrave Macmillan, (pp.549).

Bishop, A. \& Henkel, D. (1962). The measurement of soil properties in the triaxial test. $\left(2^{\text {nd }}\right.$ Ed.). London, Arnold, (pp.228).

Blankespoor, B., Dasgupta, S. \& Laplante, B. (2014). Sea-Level Rise and Coastal Wetlands. Ambio, 43, 996-1005.

British Standards Institution (BSI) (1990). Part 7: Shear strength tests (total stress). BS 1377. London, British Standard Institution, (pp.48).

British Standards Institution (BSI) (2015). Code of Practise for Ground Investigations. BS 5930. London, British Standards Institution. (pp.318).

Burningham, H., \& French, J. (2011). Seabed dynamics in a lage coastal embayment: 180 years of morphological change in the outer Thames 
estuary. Hydrobiologia, 672(1), 105-119.

Callaway, J. C., DeLaune, R. D. \& Patrick, W. H. (1996). Chernobyl 137Cs used to determine sediment accretion rates at selected northern European coastal wetlands. Limnology and Oceanography, 41(3), 444-450.

Chen, X. D., Zhang, C. K., Paterson, D. M., Thompson, C. E. L., Townend, I. H., Gong, Z., Zhou, Z. \& Feng, Q. (2017). Hindered erosion: The biological mediation of noncohesive sediment behavior. Water Resources Research, 53(6), 4787-4801.

Crooks, S. \& Pye, K. (2000). Sedimentological controls on the erosion and morphology of saltmarshes: implications for flood defence and habitat recreation. In: Pye, K. \& Allen, J. R. L. (Eds.), Coastal and Estuarine Environments: sedimentology, geomorphology and geoarchaeology. Special Publications, Vol.175. London, Geological Society, (pp.207-222)

Crooks, S., Herr, D., Tamelander, J., Laffoley, D. \& Vandever, J. (2011). Mitigating climate change through restoration and management of coastal wetlands and near-shore marine ecosystems: Challenges and opportunities. Paper 121, Washington D.C., World Bank Environment Department, (pp.59).

Crosby, S. C., Sax, D. F., Palmer, M. E., Booth, H. S., Deegan, L. A., Bertness, M. D. \& Leslie, H. M. (2016). Salt marsh persistence is threatened by predicted sea-level rise. Estuarine, Coastal and Shelf Science, 181, 93-99.

Elschot, K., Bouma, T. J., Temmerman, S. \& Bakker, J. P. (2013). Effects of long-term grazing on sediment deposition and salt-marsh accretion rates. Estuarine, Coastal and Shelf Science, 133, 109-115.

Evans, B. R. (2018). Data-driven prediction of saltmarsh morphodynamics. University of Cambridge. Unpublished PhD Thesis, (pp.298).

Hoek, E. \& Bray, J. (1974). Rock Slope Engineering. London, The Institution of Mining and Metallurgy, Unwin Brothers Limited, (pp.309).

Feagin, R. A., Lozada-Bernard, S. M., Ravens, T. M., Möller, I., Yeager, K. M. \& Baird, A. H. (2009). Does vegetation prevent wave erosion of salt marsh edges? Proceedings of the National Academy of Sciences, 106(25), 10109-10113.

Ford, H., Garbutt, A., Ladd, C., Malarkey, J. \& Skov, M. W. (2016). Soil stabilization linked to plant diversity and environmental context in coastal wetlands. Journal of Vegetation Science, 27(2), 259-268. 
Gray, A. J. (1972). The Ecology of Morecambe Bay. V. The Salt Marshes of Morecambe Bay. Journal of Applied Ecology, 9(1), 207-220.

Harmsworth, G. C. \& Long, S. P. (1986). An assessment of saltmarsh erosion in Essex, England, with reference to the Dengie Peninsula. Biological Conservation, 35(4), 377-387.

Hight, D. W., Paul, M. A., Barras, B. F., Powell, J. J. M., Nash, D. F. T., Smith, P. R., Jardine, R. J. \& Edwards, D. H. (2003). The characterisation of the Bothkennar clay. In: Tan et al. (eds.) Proceedings of the International Workshop on Characterisation and Engineering Properties of Natural Soils, Vol. 2, CRC Press, (pp. 543-597).

Howes, N. C., FitzGerald, D. M., Hughes, Z. J., Georgiou, I. Y., Kulp, M. A., Miner, M. D., Smith, J. M. \& Barras, J. A. (2010). Hurricane-induced failure of low salinity wetlands. PNAS, 107(32), 14014-14019.

Hunt, S., Bryan, K. R. \& Mullarney, J. C. (2015). The influence of wind and waves on the existence of stable intertidal morphology in meso-tidal estuaries. Geomorphology, 228, 158-174.

Kara, E. M., Meghachou, M. \& Aboubekr, N. (2013). Contribution of Particles Size Ranges to Sand Friction. Engineering, Technology \& Applied Science Research, 3(4), 497-501.

Kirwan, M. L., Guntenspergen, G. R., D'Alpaos, A., Morris, J. T., Mudd, S. M. $\&$ Temmerman, S. (2010). Limits on the adaptability of coastal marshes to rising sea level. Geophysical Research Letters, 37(23), 1-5.

Knappett, J. A. \& Craig, R. F. (2012). Craig's Soil Mechanics (8th Ed.). London CRC Press, (pp.584).

Lambert, R. (2000). Practical management of grazed saltmarshes. In: Sherwood, B. R., Gardiner, B. G. \& Harris, T. (Eds.) British Saltmarshes. London, Forrest Text, (pp. 333-340).

Lehane, B. M. \& Jardine, R. J. (1992). Residual strength characteristics of Bothkennar clay. Géotechnique, 42(2), 363-367.

Leonardi, N., Carnacina, I., Donatelli, C., Ganju, N. K., Plater, A. J., Schuerch, M. \& Temmerman, S. (2018). Dynamic interactions between coastal storms and salt marshes: A review. Geomorphology, 301, 92-107.

Leonardi, N. \& Fagherazzi, S. (2014). How waves shape salt marshes. Geology, $42(10), 887-890$. 
Lupini, J. F., Skinner, A. E. \& Vaughan, P. R. (1981). The drained residual strength of cohesive soils. Geotechnique, 31(2), 181-213.

Mariotti, G. \& Fagherazzi, S. (2013). Critical width of tidal flats triggers marsh collapse in the absence of sea-level rise. Proceedings of the National Academy of Sciences, 110(14), 5353-5356.

McLeod, E., Chmura, G. L., Bouillon, S., Salm, R., Björk, M., Duarte, C. M., Lovelock, C. E., Schlesinger, W. H. \& Silliman, B. R. (2011). A blueprint for blue carbon: Toward an improved understanding of the role of vegetated coastal habitats in sequestering $\mathrm{CO} 2$. Frontiers in Ecology and the Environment, 9(10), 552-560.

Möller, I. (2006). Quantifying saltmarsh vegetation and its effect on wave height dissipation: Results from a UK East coast saltmarsh. Estuarine, Coastal and Shelf Science, 69(3-4), 337-351.

Möller, I. \& Spencer, T. (2002). Wave dissipation over macro-tidal saltmarshes: Effects of marsh edge typology and vegetation change. Journal of Coastal Research, 36(36), 506-521.

Möller, I., Kudella, M., Rupprecht, F., Spencer, T., Paul, M., van Wesenbeeck, B. K., Wolters, G., Jenses, K., Bouma, T. J., Miranda-Lange, M. \& Schimmels, S. (2014). Wave attenuation over coastal salt marshes under storm surge conditions. Nature Geoscience, 7, 727-731.

OS (2018). OS VectorMap ${ }^{\mathrm{TM}}$ District SHAPE data, Scale 1:25000, Tiles: sd, tm. Updated: 30 April 2018, Ordnance Survey (GB), Using: EDINA Digimap OS Service, https://digimap.edina.ac.uk, Downloaded: 2019-02-11

Pringle, A. W. (1995). Erosion of a cyclic saltmarsh in Morecambe Bay, NorthWest England. Earth Surface Processes and Landforms, 20(5), 387-405.

Pye, K. (2000). Saltmarsh erosion in southeast England: mechanisms, causes and implications. In: Sherwood, B. R., Gardiner, B. G. \& Harris, T. (Eds.), British Saltmarshes. Linnean Society of London, (pp. 359-396).

Reed, J. (1988). Sediment Retreating Dynamics and Deposition in a Retreating Coastal Salt Marsh. Estuarine, Coastal and Shelf Science, 26(1), 67-79.

Rupprecht, F., Möller, I., Evans, B., Spencer, T. \& Jensen, K. (2015). Biophysical properties of salt marsh canopies - Quantifying plant stem flexibility and above ground biomass. Coastal Engineering, 100, 48-57.

Shennan, I. \& Horton, B. (2002). Holocene land- and sea-level changes in Great 
Britain. Journal of Quaternary Science, 17(5-6), 511-526.

Spencer, T., Brooks, S. M., Möller, I. \& Evans, B. R. (2014). Where local matters: Impacts of a major north sea storm surge. Eos, 95(30), 269-270.

Spencer, T., Brooks, S. M., Evans, B. R., Tempest, J. A. \& Möller, I. (2015). Southern North Sea storm surge event of 5 December 2013: Water levels, waves and coastal impacts. Earth-Science Reviews, 146, 120-145.

Spencer, T., Schuerch, M., Nicholls, R. J., Hinkel, J., Lincke, D., Vafeidis, A. T., Reef, R., McFadden, L. \& Brown, S. (2016). Global coastal wetland change under sea-level rise and related stresses: The DIVA Wetland Change Model. Global and Planetary Change, 139, 15-30.

Terzaghi, K., Peck, R. B. \& Mesri, G. (1996). Soil Mechanics in Engineering Practice (3rd Ed.). Chichester, Wiley, (pp.592).

Thompson, C. E. L., Williams, M. E., Amoudry, L., Hull, T., Reynolds, S., Panton, A., \& Fones, G. R. (in press). Benthic controls of resuspension in UK shelf seas: Implications for resuspension frequency. Continental Shelf Research, 1-13.

Tiwari, B. \& Marui, H. (2005). A New Method for the Correlation of Residual Shear Strength of the Soil with Mineralogical Composition. Journal of Geotechnical and Geoenvironmental Engineering, 131(9), 1139-1150.

Tolhurst, T. J., Black, K. S., Shayler, S. A., Mather, S., Black, I., Baker, K. \& Paterson, D. M. (1999). Measuring the in situ Erosion Shear Stress of Intertidal Sediments with the Cohesive Strength Meter (CSM). Estuarine, Coastal and Shelf Science, 49(2), 281-294.

Widdows, J., Brown, S., Brinsley, M. D., Salkeld, P. N. \& Elliott, M. (2000). Temporal changes in intertidal sediment erodability: Influence of biological and climatic factors. Cont. Shelf Research, 20, 1275-1289.

Willemsen, P. W. J. M., Borsje, B. W., Hulscher, S. J. M. H., Van der Wal, D., Zhu, Z., Oteman, B., Evans, B., Moeller, I. \& Bouma, T. J. (2018). Quantifying bed level change at the transition of tidal flat and salt marsh: can we understand the lateral location of the marsh edge? Journal of Geophysical Research: Earth Surface, 123, 1-16.

Wood, C. L., Hawkins, S. J., Godbold, J. A. \& Solan, M. (2015). Coastal Biodiversity and Ecosystem Service Sustainability sediment particle size in mudflat and saltmarsh habitats. NERC Environmental Information Data Centre. https://doi.org/10.5285/4e6a2e58-6916-4212-8b2e-e30942b0a05a 